\title{
Epidemiological Overview of Sleep Disorders in the General Population
}

\author{
Maurice M. Ohayon, MD, DSc, PhD \\ Stanford Sleep Epidemiology Research Center, School of Medicine, Stanford University, Stanford, CA, USA
}

\begin{abstract}
There are several hundred of epidemiological studies assessing different sleep complaints and disorders in the general population. This article summarizes the main findings of these studies and underlines some of the aspects that still need to be investigated. Insomnia complaint is one of the most studied sleep disturbances. Nearly one third of the general population complains of insomnia but a diagnosis is warranted in only $6 \%$ to $15 \%$ of the population. Excessive sleepiness is also another frequent complaint. However, its definition and method of assessment are so diverse that it is difficult to have a clear estimate of its prevalence in the general population: prevalence rates are ranging between $4 \%$ and $26 \%$. Narcolepsy is a rare disorder with a prevalence averaging $0.04 \%$ in the general population. Obstructive Sleep Apnea Syndrome, often associated with insomnia or excessive sleepiness, is found in approximately $2 \%$ to $4 \%$ of the general population and has a higher prevalence in men than in women. Restless legs syndrome (RLS), depending on how it was assessed, varies from a low $1 \%$ in Asian countries to a high $19 \%$ in Northern European countries. RLS is higher in women and increases with age. Unfortunately, despite the high prevalence, sleep disorders remain poorly identified; less than $20 \%$ of individuals with insomnia are correctly diagnosed and treated. The figures are even lower for excessive sleepiness and RLS with less than $10 \%$ correctly diagnosed and treated.

Sleep Med Res 2011;2:1-9
\end{abstract}

Key Words Sleepiness, Nacrolepsy, Restless legs syndrome, Insomnia, Prevalence.

Received: March 24, 2011 Accepted: March 24, 2011

Correspondence

Maurice M. Ohayon, MD, DSc, PhD

Stanford Sleep Epidemiology

Research Center, School of Medicine,

Stanford University, 3430 W. Bayshore Road,

Palo Alto, CA 94303, USA

Tel +1-650-494-1137

Fax +1-650-947-9813, 1-650-493-1225

E-mail mohayon@stanford.edu

\section{INTRODUCTION}

Each of us will spend about 27 years of his or her lifetime sleeping. This fact alone explains why neuro-anatomists and neuro-physiologists have been studying sleep for over a century. The epidemiology of sleep, however, is a relatively young field of study, although physicians have always been interested in knowing how widespread abnormal sleep phenomena are in the population. The field of sleep disorders encompasses a broad range of phenomena; such as insomnia, excessive sleepiness, sleep apnea and many other sleep disorders. They are traditionally divided into two broad categories: dyssomnias and parasomnias. The dyssomnias are characterized by abnormalities in the quantity or quality of sleep and its cycles. They are associated with difficulty initiating or maintaining sleep or excessive sleepiness.

This article focuses on sleep disorders most often studied in the general population. It is divided into four main topics: insomnia and its disorders, excessive sleepiness and its disorders, breathing-related sleep disorders and restless legs syndrome (RLS).

\section{INSOMNIA AND ITS DISORDERS}

Over 50 epidemiological studies of insomnia have been conducted worldwide. ${ }^{1}$

To date, there is no consensus on how to define insomnia in the general population. Consequently, the prevalence rates for insomnia in the general population vary greatly depending on the definition used. However, the epidemiological approach to measure insomnia can be summarized into two broad categories 1) dissatisfaction with sleep quantity 2) dissatisfaction with the 
quality of sleep.

Dissatisfaction with sleep quantity can be expressed as a complaint of insufficient sleep. Lack of sleep has a prevalence rate between $20 \%$ and $41.7 \%$ in the general population.

Dissatisfaction with the quality of sleep is defined in several ways. It can be expressed as a complaint of difficulty initiating sleep (DIS), difficulty maintaining sleep (DMS), nocturnal awakening with difficulty or inability resuming sleep or non-restorative sleep.

The evaluation of DIS or DMS is done using mainly in four strategies: 1) asking participants for the presence of any of these symptoms, 2) what was the frequency of symptoms per week, 3) what was their severity, and 4) what were the consequences on daytime functioning.

Each of these strategies provided different prevalences. Studies limited to the simple evaluation of the presence / absence of DIS or DMS reported high prevalences ranging from $30 \%$ to $48 \%{ }^{1}$

Currently, most epidemiological studies have measured the weekly frequency of DIS and DMS. Generally, a frequency of three or more nights per week was used to determine the presence of symptoms. Other studies have used a qualitative assessment of the frequency like "sometimes" "often" or "always"; often or always being the threshold for determining the presence of DIS or DMS. The prevalence of DIS or DMS varies between $16 \%$ and $21 \%$ when this method is used. ${ }^{1}$

The qualitative assessment of the severity of DIS or DMS (such as being extremely or very annoyed by DIS or DMS) gave a prevalence of DIS/DMS between $10 \%$ and $28 \%$ of the general population. ${ }^{1}$

Some epidemiological studies, in addition to assessing the presence, frequency or severity of insomnia symptoms, also addressed their associations with daytime symptoms such as sleepiness, cognitive impairment, irritability, mood swings, anxiety, or medical consultations. The combined presence of symptoms and their con- sequences provides significantly lower prevalences ranging from $8.5 \%$ and $13.0 \%{ }^{1}$

Several epidemiological studies have assessed the level of sleep satisfaction of participants. The prevalence of individuals dissatisfied with their sleep varies from $8 \%$ to $18.5 \%$. ${ }^{1}$ Other studies have examined the perception of sleep quality or asked whether participants considered themselves as insomniacs: between $10 \%$ and $18.1 \%$ of the population reported to be poor sleepers or insomniacs. ${ }^{1}$

The diagnostic evaluation of insomnia in the general population is uncommon. The few studies that evaluated prevalence of insomnia diagnosis reported rates ranging from $4.4 \%$ to $11.7 \%{ }^{1}$

Chronicity of insomnia complaint in the general population is poorly documented. ${ }^{1,2}$ Yet, studies have shown that insomnia was most chronic and lasted at least one year in $85 \%$ of cases. ${ }^{2}$

\section{Factors Associated with Insomnia}

Several other diseases then insomnia disorders can lead to an insomnia complaint. For example, breathing-related sleep disorders such as sleep apnea or sleep hypoventilation account for $5 \%$ to $9 \%$ of insomnia complaints. Periodic limb movement disorders and / or RLS are found in about 15\% of individuals complaining of insomnia. Neurological or medical conditions are observed in $4 \%$ to $11 \%$ of insomnia complaints. Poor sleep hygiene or environmental factors account for approximately $10 \%$ of insomnia complaints. Insomnia associated with the use of a psychoactive substance account for 3\% to $7 \%$ of insomnia complaints (Fig. 1).

\section{Mental Disorders}

The association between mental disorders and insomnia is well known: Epidemiological studies have shown that between 30 and $60 \%$ of people with mental disorders also complain of insomnia. Some studies have shown that up to $80 \%$ of individuals with major depressive disorder suffer from insomnia. ${ }^{3-5}$ Four longitudinal

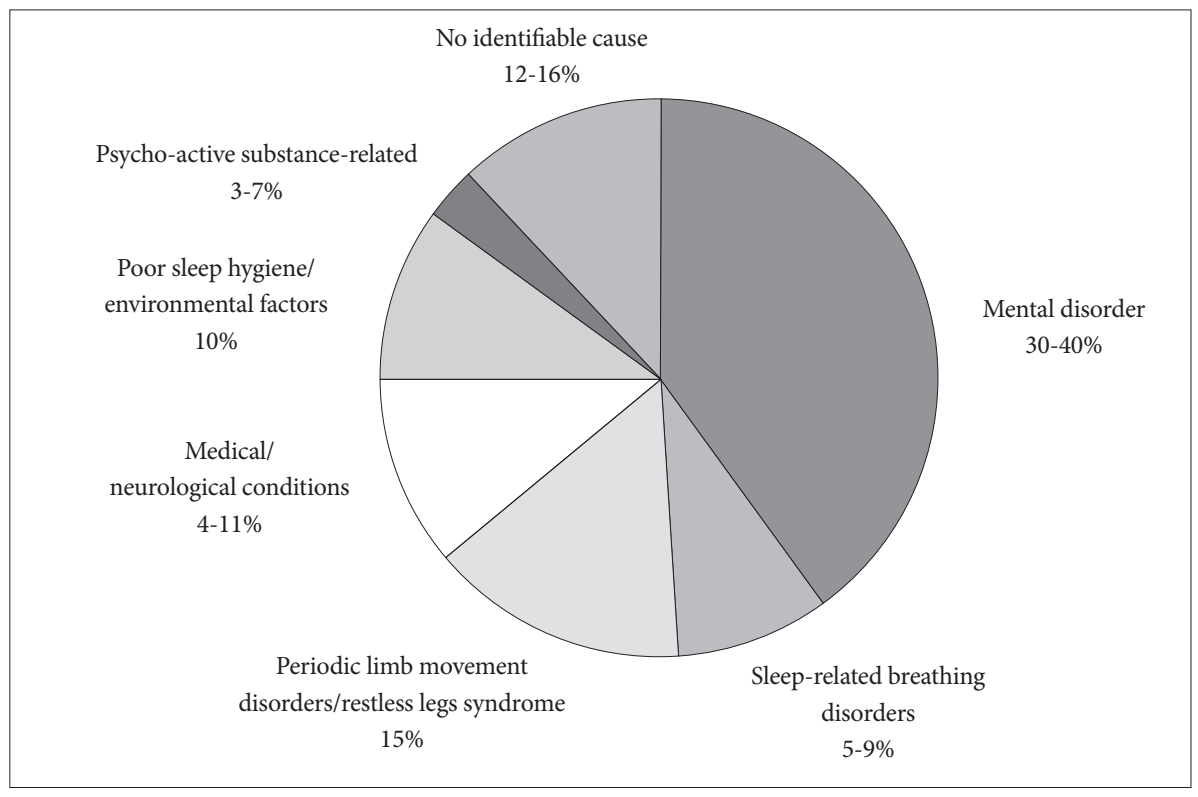

Fig. 1. Diagnostic distribution of insomnia complaints. 
studies have examined the relationship between the persistence of insomnia and the onset of mental disorders. ${ }^{6-11}$ The persistence of insomnia over time was associated with a likelihood of four to eight times higher of developing a mental disorder.

\section{Physical Illnesses and the Use of Psychoactive Substances}

People who complain of insomnia frequently reported being in poor health. Some studies have found that nearly half of those with insomnia symptoms have multiple persistent or chronic health problems. The associations most frequently reported are with upper airway diseases, rheumatic diseases, chronic pain and cardiovascular diseases. ${ }^{1,12}$ Several epidemiological studies have observed that the use of tobacco, alcohol and antihypertensive drugs were significantly associated with insomnia symptoms. In these populations, alcohol was used as a means to promote sleep by about $40 \%$ of individuals with insomnia. ${ }^{13}$

\section{Age and Sex}

In the general population, the prevalence of DIS and DMS increases linearly with age reaching nearly $50 \%$ among individuals older than 65 years. ${ }^{1}$ However, this linear increase is not universally found in studies evaluating DIS or DMS accompanied with daytime consequences and in those measuring sleep dissatisfaction. Women are more likely than men to complain of DIS or DMS, daytime consequences, sleep dissatisfaction and to have insomnia diagnoses. ${ }^{1}$ Some studies have shown a high prevalence of insomnia in menopausal women compared to those in pre-menopause. $^{14,15}$

\section{Lifestyle}

Several factors related to lifestyle are associated with an increased risk for insomnia in the general population. Such is the case of people who report having a very stressful life, ${ }^{16,17}$ unemployed, or shift workers ${ }^{19}$ and people sleeping in a bedroom with inadequate temperature. $^{16}$

\section{EXCESSIVE SLEEPINESS AND ITS DISORDERS}

The term excessive sleepiness is often used interchangeably with hypersomnia. This procedure is partially correct; hypersomnia is a disorder including a variety of symptoms such as prolonged nocturnal sleep, naps and inability to stay awake or alert in situations where alertness is required (excessive sleepiness). There is also a growing tendency to label excessive sleepiness as a disease or disorder. To date, there are no data supporting this practice. According to the current classifications, excessive sleepiness is not a disease; it is a symptom of a sleep disorder or another illness. In the International Classification of Sleep Disorders, exces- sive sleepiness is listed as a main characteristic (i.e., mandatory for diagnosis) for only three sleep disorders: behaviorally induced insufficient sleep syndrome, hypersomnia (idiopathic, chronic or posttraumatic) and Narcolepsy.

In most cases, studies that evaluated excessive sleepiness in the general population can be divided into two categories: those that measure the excessive amount of sleep and those assessing the tendency to fall asleep during wakefulness. ${ }^{20}$

The tendency to fall asleep during waking in situations of diminished attention refers to excessive sleepiness. Its definition and assessment vary almost as much as the number of epidemiological studies having investigated it. Most studies have assessed excessive sleepiness with a single question. Depending on the study, this question received a yes or no, or was answered on a severity or a frequency scale. The duration of excessive sleepiness has rarely been examined.

Many studies only verifying the presence or absence of excessive sleepiness were made with subjects aged 65 and over. ${ }^{20}$ In studies based on the entire adult population, the prevalence of excessive sleepiness using yes/no answer usually ranged between $3.9 \%$ and $16 \%$. For example, a study in the general population of Mexico reported a prevalence of $21.5 \%$ and another study in Japan has achieved a rate of $2.5 \%$.

The frequency of excessive sleepiness was assessed using either a scale ranging from never to very often or always, or using a graduate scale of symptoms frequency during the week.

Prevalence of individuals reporting being often or very often sleepy during the day ranged between $5 \%$ and $26 \%$ of the population, the highest rates being found in Poland and Japan. Excessive sleepiness occurring at least three days per week was reported with rates varying between $4 \%$ and $20.6 \%$ in Europe. ${ }^{20}$ The great variability of results is largely due to the different formulations of questions to assess excessive sleepiness.

There are few studies in the general population who have compared different types of questions assessing excessive sleepiness. A study ${ }^{21}$ showed that three measures of subjective sleepiness had a moderate correlation between them ( $\mathrm{r}$ between 0.22 and 0.35 ). Another study ${ }^{22}$ showed that the results obtained in the Epworth Sleepiness Scale corresponded moderately with other measures of subjective excessive sleepiness (feeling sleepy during the day ( $\mathrm{r}$ $=0.36)$ or feel tired during day $(\mathrm{r}=0.24)$.

Unlike symptoms of insomnia, excessive sleepiness is not gender-related in several studies. The lack of consistent definition of excessive sleepiness leads to unacceptable variability in prevalence rates. Whether its prevalence increases or decreases with age is not clear, as both trends have been observed. ${ }^{20}$ Excessive sleepiness can be caused by various factors such as poor sleep hygiene, work conditions, and psychotropic medication use. It has been found to be associated also with breathing-related sleep disorders, psychiatric disorders, especially depression, and physical illnesses. ${ }^{20}$ 


\section{Narcolepsy}

There have been some attempts to estimate the prevalence of narcolepsy in different parts of the world. ${ }^{20,23}$ Most prevalences are derived from clinical samples or unrepresentative of the general population. Only three studies are based on representative samples of people. According to these studies, the prevalence of narcolepsy ranges from 20 to 67 per 100,000 inhabitants with narcolepsy in Europe and North America. A study in Japan estimated this figure at 590 narcoleptics per 100,000 inhabitants and another Japanese study has established that rate to 160 per 100,000 inhabitants. In Hong Kong, the prevalence was estimated to be between 1 and 40 narcoleptics per 100,000 inhabitants while in Saudi Arabia this rate would amount to 40 per 100,000 inhabitants. Another study with Jewish Israelis, a population known for its low rate of human leukocyte antigen (HLA-DR2) a marker of narcolepsy, established the prevalence at 0.23 per 100,000 inhabitants.

\section{BREATHING-RELATED SLEEP DISORDERS}

Sleep apnea is characterized by repeated breathing cessations during sleep lasting at least 10 seconds. The number of apnea and hypopnea (respiratory disturbances) events per hour, called the respiratory disturbance index (RDI) or apnea/hypopnea index (AHI), is used to determine whether breathing patterns are abnormal. Usually, an AHI of 5 or more is considered an indicator

Table 1. Prevalence of sleep apnea syndrome in community-based studies

\begin{tabular}{|c|c|c|c|c|}
\hline Authors, place & $\mathrm{n}(\mathrm{n}$ recorded $)$ & Age range & Criteria & Prevalence \\
\hline Lavie, ${ }^{24}$ Israel & $1502(78)$ & $32-67 \mathrm{M}$ & $\mathrm{AI} \geq 10$ & $0.89 \%$ \\
\hline Gislason et al., ${ }^{24}$ & $3201(61)$ & $30-69 \mathrm{M}$ & $\mathrm{AHI} \geq 30+$ excessive sleepiness & $1.3 \%$ \\
\hline \multicolumn{5}{|l|}{ Uppsala, Sweden } \\
\hline Cirignotta et al., ${ }^{26}$ & $1170(40)$ & $30-69 \mathrm{M}$ & $\mathrm{AHI} \geq 10$ & $2.7 \%$ \\
\hline \multicolumn{5}{|l|}{ Bologna, Italy } \\
\hline Martikainen et al., ${ }^{27}$ & 1985: 1190 & $36-50$ & ODI $\geq 4 \%>5$ per hour & $1.8 \%$ \\
\hline Tempere, Finland & 1990: $626(22)$ & & ODI $\geq 4 \%>10$ per hour & $1.1 \%$ \\
\hline Ancoli-Israel et al., ${ }^{28}$ & $615(427)$ & $65-95$ & $\mathrm{AI} \geq 5$ & $24.0 \%$ \\
\hline San Diego, USA & & & $\mathrm{RDI} \geq 10$ & $62.0 \%$ \\
\hline Stradling \& Cosby, ${ }^{29}$ & $1001(893)$ & $35-65 \mathrm{M}$ & ODI $\geq 4 \%>5$ per hour & $5.0 \%$ \\
\hline \multirow[t]{2}{*}{ Oxford, UK } & & & ODI $\geq 4 \%>10$ per hour & $1.0 \%$ \\
\hline & & & ODI $\geq 3 \%>10$ per hour + symptoms & $0.8 \%$ \\
\hline Gislason et al., ${ }^{30}$ & $1505(35)$ & $40-59 \mathrm{~W}$ & $\mathrm{AHI} \geq 30+$ excessive sleepiness & $2.5 \%$ \\
\hline \multicolumn{5}{|l|}{ Reykjavik, Iceland } \\
\hline Young et al., ${ }^{31}$ & $3513(625)$ & $30-60$ & $\mathrm{AHI} \geq 5$ & $4.0 \%(\mathrm{M})$ \\
\hline USA & & & & $2.0 \%(\mathrm{~W})$ \\
\hline Olson et al., 32 & $2202(441)$ & $35-69$ & $\mathrm{AHI} \geq 10$ & $5.7 \%(\mathrm{M})$ \\
\hline Australia & & & & $1.2 \%(\mathrm{~W})$ \\
\hline Bearpark et al., ${ }^{33}$ & $486(294)$ & $40-65 \mathrm{M}$ & $\mathrm{RDI} \geq 5+$ at least occasional excessive sleepiness & $12.2 \%$ \\
\hline Busselton, Australia & & & RDI $\geq 5+$ at least often excessive sleepiness & $3.1 \%$ \\
\hline Bixler et al., ${ }^{34}$ & $4364(741)$ & $20-100 \mathrm{M}$ & $\mathrm{AHI} \geq 10+$ daytime symptoms & $3.3 \%$ \\
\hline $\begin{array}{l}\text { Pennsylvania, USA } \\
\text { Bixler et al., }{ }^{35}\end{array}$ & $12,219(1,000)$ & $20-100 \mathrm{~W}$ & $\mathrm{AHI} \geq 10+$ daytime symptoms & $1.2 \%$ \\
\hline \multicolumn{5}{|l|}{ Pennsylvania, USA } \\
\hline Duran et al., 36 & $2148(555)$ & $30-70$ & $\mathrm{AHI} \geq 10$ & $19.0 \%(\mathrm{M})$ \\
\hline Vitoria-Gasteiz, Spain & & & & $14.9 \%(\mathrm{~W})$ \\
\hline Ip et al., ${ }^{37}$ & $1532(106)$ & $30-60 \mathrm{~W}$ & $\mathrm{AHI} \geq 5$ & $3.7 \%$ \\
\hline Hong Kong & & & $\mathrm{AHI} \geq 5+$ excessive sleepiness & $2.1 \%$ \\
\hline Udwadia et al., ${ }^{38}$ & $658(250)$ & $35-65 \mathrm{M}$ & $\mathrm{AHI} \geq 5$ & $19.5 \%$ \\
\hline Bombay, India & & & $\mathrm{AHI} \geq 5+$ excessive sleepiness & $7.5 \%$ \\
\hline Sharma et al., ${ }^{39}$ & $2,150(150)$ & $30-60$ & $\mathrm{AHI} \geq 5$ & $13.7 \%$ \\
\hline Semi-urban community of Delhi, India & & & $\mathrm{AHI} \geq 5+$ excessive sleepiness & $3.57 \%$ \\
\hline Reddy et al., ${ }^{40}$ & $2,505(360)$ & $30-65$ & $\mathrm{AHI} \geq 5$ & $9.3 \%$ \\
\hline South Delhi, India & & & AHI $\geq 5+$ excessive sleepiness & $2.8 \%$ \\
\hline
\end{tabular}

M: men, W: women, AI: apnea index, AHI: apnea/hypopnea index, ODI: oxygen desaturation index, RDI: respiratory disturbance index. 
Table 2. Prevalence of Restless Legs Syndrome in community-based studies

\begin{tabular}{|c|c|c|c|}
\hline Authors, Place & $\mathrm{n}$ & Age range & Prevalence \\
\hline \multicolumn{4}{|c|}{ Restless Legs Syndrome assessed with 1 or 2 questions } \\
\hline Lavigne \& Montplaisir, ${ }^{41}$ Canada & 2,019 & $\geq 18$ & $10 \%$ to $15 \%$ \\
\hline Phillips et al., ${ }^{42}$ Kentucky, USA & 1,803 & $\geq 18$ & $9.4 \%$ \\
\hline Kageyama et al., ${ }^{43}$ & 4,612 & $\geq 20$ & $3-7 \% \mathrm{~W}$ \\
\hline 5 cities, Japan & & & $4-10 \% \mathrm{M}$ \\
\hline Rijsman et al., ${ }^{44}$ Krimpen, Netherlands & 1,437 & $50-109$ & $7.1 \%$ \\
\hline Kim et al., ${ }^{45}$ South Korea & 9,939 & $40-69$ & $12.1 \%$ \\
\hline Elwood et al., ${ }^{46}$ Caerphilly, South Wales, UK & $1,986 \mathrm{M}$ & $55-69$ & $23.0 \%$ \\
\hline Phillips et al., ${ }^{47}$ USA & 1,506 & $\geq 18$ & $9.7 \%$ \\
\hline Yokoyama et al., ${ }^{48}$ Japan & 1,769 & $\geq 70$ & $11.4 \%$ \\
\hline Juuti et al., ${ }^{49}$ Oulu, Finland & 995 & 57 & $18.0 \%$ \\
\hline \multicolumn{4}{|c|}{1995 International Restless Legs Syndrome Study Group criteria } \\
\hline Rothdach et al., ${ }^{50}$ Augsburg, Germany & 369 & $65-83$ & $9.8 \%$ \\
\hline Ulfberg et al., ${ }^{51}$ Dalarna County, Sweden & $2,608 \mathrm{M}$ & $18-64$ & $5.8 \%$ \\
\hline Ulfberg et al., ${ }^{52}$ Dalarna County, Sweden & $140 \mathrm{~W}$ & $18-64$ & $11.4 \%$ \\
\hline Sevim et al., ${ }^{53}$ Mersin, Turkey & 3,234 & $\geq 18$ & $3.2 \%$ \\
\hline Berger et al., ${ }^{54}$ Pomerania, Germany & 4,310 & $20-79$ & $10.6 \%$ \\
\hline Högl et al., ${ }^{55}$ Bruneck, Italy & 701 & $50-89$ & $10.6 \%$ \\
\hline Mizuno et al. ${ }^{56}$ Izumo city, Japan & 3,287 & $\geq 65$ & $1.06 \%$ \\
\hline Tison et al., ${ }^{57}$ France & 10,263 & $\geq 18$ & $8.5 \%$ \\
\hline Gao et al., 58 & $65,554 \mathrm{~W}$ & W: $38-55$ & $\geq 5 \mathrm{t} / \mathrm{mth}(\geq 15 \mathrm{t} / \mathrm{mth}):$ \\
\hline \multirow[t]{2}{*}{14 states in USA } & $23,119 \mathrm{M}$ & $\mathrm{M}:>56$ & $\mathrm{~W}: 6.4 \%(2.7 \%)$ \\
\hline & & & M: $4.1 \%(1.7 \%)$ \\
\hline Tsuboi et al., ${ }^{59}$ Ajimu, Japan & 1,251 & $\geq 65$ & $0.96 \%$ \\
\hline \multicolumn{4}{|c|}{2003 International Restless Legs Syndrome Study Group criteria } \\
\hline Allen et al., ${ }^{60}$ & 15,391 & $\geq 18$ & $7.2 \%$ \\
\hline USA + 5 European countries & & & $\begin{array}{c}2.7 \%(\geq 2 \mathrm{t} / \mathrm{wk}+\text { moderate/ } \\
\text { severe distress })\end{array}$ \\
\hline \multirow[t]{2}{*}{ Bjorvatn et al., ${ }^{61}$ Denmark \& Norway } & 2,005 & $\geq 18$ & 8.8\% Denmark \\
\hline & & & $14.3 \%$ Norway \\
\hline Castillo et al. ${ }^{62}$ & 500 & $25-85$ & $3.2 \%$ Quito \\
\hline Guayaquil and Quito cities, Ecuador & & & $0.8 \%$ Guayaquil \\
\hline Lee et al., ${ }^{63}$ Baltimore, USA & 1,028 & $58( \pm 12)$ & $4.2 \%$ \\
\hline Vogl et al. ${ }^{64}$ South Tyrol & 530 & $\geq 18$ & $8.9 \%$ \\
\hline Hadjigeorgiou et al., ${ }^{65}$ Larissa, Greece & 3,033 & $\geq 20$ & $3.9 \%$ \\
\hline Rangarajan et al., ${ }^{66}$ Bangalore, India & 1,266 & $18-90$ & $2.1 \%$ \\
\hline Ulfberg et al., ${ }^{67}$ Sweden & 1,000 & $18-90$ & $5.0 \%$ \\
\hline Broman et al., ${ }^{68}$ & 1,335 & $20-59$ & $18.8 \%$ \\
\hline Uppsala, Sweden & & & $5.8 \%(\geq 2 \mathrm{t} / \mathrm{wk})$ \\
\hline Cho et al. ${ }^{69} 5$ regions, South Korea & 5,000 & $20-69$ & $7.5 \%$ \\
\hline Froese et al., ${ }^{70}$ British Columbia, Canada & 430 & $\geq 18$ & $17.7 \%$ \\
\hline Happe et al., ${ }^{71}$ Dortmund, Germany & 1,312 & $25-75$ & $8.8 \%$ \\
\hline Nomura et al., ${ }^{72}$ Daisen, Japan & 2,812 & $\geq 20$ & $1.8 \%$ \\
\hline Wesström et al., ${ }^{73}$ Dalarna county, Sweden & $3,516 \mathrm{~W}$ & $18-64$ & $15.7 \%$ \\
\hline Winkelman et al., ${ }^{74}$ USA & 3,254 & $44-98$ & $5.2 \%$ \\
\hline
\end{tabular}


Table 2. Continued

\begin{tabular}{|c|c|c|c|}
\hline Authors, Place & $\mathrm{n}$ & Age range & Prevalence \\
\hline Cho et al., ${ }^{75}$ South Korea & 6,509 & $18-64$ & $0.9 \%$ \\
\hline Erer et al., ${ }^{76}$ Orhangazi, Bursa, Turkey & 1,124 & $40-95$ & $9.7 \%$ \\
\hline Benediktsdottir et al., ${ }^{77}$ & 769 & $\geq 40$ & $18.3 \%$ Iceland \\
\hline Reykjavik, Iceland Uppsala, Sweden & 601 & & $11.5 \%$ Sweden \\
\hline Celle et al., ${ }^{78}$ St-Etienne, France & 667 & $68.6( \pm 0.8)$ & $26.0 \%$ \\
\hline Chen et al., ${ }^{79}$ Taiwan & 4,011 & 15-70 & $1.57 \%$ \\
\hline Kim et al., ${ }^{80}$ South Korea & 714 & $\geq 65$ & $8.4 \%$ \\
\hline Park et al., ${ }^{81}$ South Korea & $1,000 \mathrm{~W}$ & $40-69$ & $6.5 \%$ \\
\hline Tasdemir et al., ${ }^{82}$ Kandira, Turkey & 2,111 & $\geq 18$ & $3.4 \%$ \\
\hline Winkler et al., ${ }^{83}$ Northern Tanzania & 7,654 & $14-110$ & $0.013 \%$ \\
\hline Yilmaz et al., ${ }^{84}$ Gaziantep, Turkey & 3,304 & $15-18$ & $3.6 \%$ \\
\hline \multicolumn{4}{|l|}{ Other criteria } \\
\hline Ohayon and Roth, ${ }^{85} 5$ European countries & 18,980 & $15-100$ & ICSD: $5.5 \%$ \\
\hline Picchietti et al. ${ }^{86}$ UK and USA & 10,523 & $8-17$ & $\begin{array}{c}\text { Pediatric NIH criteria } \\
1.9 \% \text { 8-11 y.o. } \\
2.0 \% 12-17 \text { y.o. }\end{array}$ \\
\hline Ram et al., ${ }^{87}$ USA & 6,139 & $\geq 16$ & Physician-diagnosed: $0.4 \%$ \\
\hline
\end{tabular}

ICSD: International Classification of Sleep Disorders, RLS: restless legs syndrome.

of an inordinate number of sleep respiratory disturbances. Few studies have estimated the prevalence of sleep apnea or obstructive sleep apnea syndrome from representative samples of the general community (Table 1). The target population, methods, and criteria vary considerably between studies. In all cases, the prevalence rates are estimates because it is nearly impossible to perform polysomnographic recordings for all participants. Screening questionnaires were first used to identify participants most likely to have sleep apnea or Obstructive Sleep Apnea Syndrome and then polysomnographic recordings were conducted to confirm the diagnosis. Obstructive sleep apnea syndrome, often associated with insomnia or excessive sleepiness, is found in $2 \%$ to $4 \%$ of the general population (Table 1) while sleep apnea (i.e., presence of sleep respiratory disturbances with or without associated symptoms) is far more frequent ranging between $9 \%$ and $24 \%$. The prevalence of Obstructive sleep apnea syndrome is about twice higher in men than in women. . $^{31,34,35,39,40}$

\section{RESTLESS LEGS SYNDROME}

RLS has been more extensively studied in the general population in the last decade. RLS studies are reported in Table 2. Nine studies ${ }^{41-49}$ assessed RLS using a limited set of questions (one or two questions). In these cases prevalence rates ranged from $7 \%$ to $23 \%$ with an average around $10 \%$ when studies included all the adult population ( $\geq 18$ y.o.)..$^{41,42,47}$ The higher prevalences were observed in older samples ( $\geq 55$ y.o.). ${ }^{46,48,49}$

Another 10 studies $^{50-59}$ used the 1995 RLS criteria proposed by the International RLS Study Group (Table 2). Five of them targeted a broad age range of the general population..$^{51-54,57}$ In these studies, the prevalence was around $8 \%$. Three studies reported very low RLS prevalence: two of them were done in $\operatorname{Japan}^{56,59}$ with people aged at least 65 years (prevalence around 1\%) and one was done in Turkey (prevalence at 3.2\%). ${ }^{53}$

A total of 26 studies ${ }^{60-84}$ used the 2003 revised RLS criteria of the International RLS Study Group (Table 2). Sixteen of them had samples targeting most of the adult general population..$^{60-62,64-67,69 \text {, }}$ 70-73,75,79,82,83 Prevalence greatly varied according to the geographic location with prevalence rates highest in Northern European countries (Norway, Sweden, Iceland) with prevalences between $14 \%$ and $19 \%$ and lowest in Asian countries with prevalence between $1 \%$ and $2 \%$ (Table 2). There are several methodological issues to consider however. For example, the participation rate greatly varied between the studies ranging from 35\% to 95\%. Furthermore, although studies were based on the same diagnostic criteria, the methodology to assess these criteria was different between the studies: some studies requested only the presence of the 4 criteria while other studies had the participants interviewed by a sleep specialist or a neurologist to eliminate disorders that mimics RLS which led to lower prevalences.

In nearly all the studies, RLS prevalence was higher in women than in men. It also increased steadily with age until 65 years in European and North American countries but not in Asian countries. In European and North American men, RLS prevalence is approximately $2 \%$ among the $20-25$ years old and reaches about $6 \%$ among men aged 65 years or older. In European and North American women, RLS prevalence is around $4.5 \%$ among the 20 - 
25 years old and reaches about $11 \%$ among those aged 65 years or older. In Asian countries, RLS prevalence is approximately 1.8\% in men and $3 \%$ in women.

\section{CONCLUSIONS}

Sleep disorders are very common in the general population but they are poorly identified: less than $20 \%$ of individuals with insomnia are correctly diagnosed and treated, despite the fact that a considerable proportion of the population is suffering from serious sleep disorders and requires medical attention. For excessive sleepiness and RLS, the figures are even worst with less than $10 \%$ correctly diagnosed and treated.

Insomnia and excessive sleepiness affect many spheres of functioning: professional, social or family life, and cause concentration and memory problems. In addition, a sleepy individual increases his risk of road, occupational or domestic accidents. The high prevalence rates of insomnia and excessive sleepiness clearly indicate that this is a major public health problem requiring education and prevention initiatives and justifying greater attention from health authorities.

In the coming years, epidemiological research efforts should focus on: 1) distinction between the various subtypes of insomnia and a better operationalization of insomnia definition, 2) for excessive sleepiness: better definition of the concept and how to measure it in the general population. To date, comparisons between studies are virtually impossible since no study evaluate excessive sleepiness in the same way. 3) Seasonal or transitional forms of insomnia and excessive sleepiness need to be examined and 4) longitudinal epidemiological studies on the evolution and consequences of insomnia and excessive sleepiness need to be conducted.

\section{Conflicts of Interest}

The author has no financial conflicts of interest.

\section{REFERENCES}

1. Ohayon MM. Epidemiology of insomnia: what we know and what we still need to learn. Sleep Med Rev 2002;6:97-111.

2. Ohayon MM, Roth T. Place of chronic insomnia in the course of depressive and anxiety disorders. J Psychiatr Res 2003;37:9-15.

3. Mellinger GD, Balter MB, Uhlenhuth EH. Insomnia and its treatment. Prevalence and correlates. Arch Gen Psychiatry 1985;42:225-32.

4. Ohayon MM, Roth T. Place of chronic insomnia in the course of depressive and anxiety disorders. J Psychiatr Res 2003;37:9-15.

5. Ohayon MM. Prevalence of DSM-IV diagnostic criteria of insomnia: distinguishing insomnia related to mental disorders from sleep disorders. J Psychiatr Res 1997;31:333-46.

6. Weissman MM, Bland RC, Canino GJ, Faravelli C, Greenwald S, Hwu HG, et al. Cross-national epidemiology of major depression and bipolar disorder. JAMA 1996;276:293-9.

7. Ford DE, Kamerow DB. Epidemiologic study of sleep disturbances and psychiatric disorders. An opportunity for prevention? JAMA 1989;262: 1479-84.

8. Breslau N, Roth T, Rosenthal L, Andreski P. Sleep disturbance and psy- chiatric disorders: a longitudinal epidemiological study of young adults. Biol Psychiatry 1996;39:411-8.

9. Roberts RE, Roberts CR, Chen IG. Impact of insomnia on future functioning of adolescents. J Psychosom Res 2002;53:561-9.

10. Roberts RE, Shema SJ, Kaplan GA, Strawbridge WJ. Sleep complaints and depression in an aging cohort: a prospective perspective. Am J Psychiatry 2000;157:81-8.

11. Ohayon MM. Observation of the natural evolution of insomnia in the American general population cohort. Sleep Med Clin 2009;4:87-92.

12. Mallon L, Broman JE, Hetta J. Sleep complaints predict coronary artery disease mortality in males: a 12-year follow-up study of a middle-aged Swedish population. J Intern Med 2002;251:207-16.

13. Roehrs T, Hollebeek E, Drake C, Roth T. Substance use for insomnia in Metropolitan Detroit. J Psychosom Res 2002;53:571-6.

14. Owens JF, Matthews KA. Sleep disturbance in healthy middle-aged women. Maturitas 1998;30:41-50.

15. Ohayon MM. Severe hot flashes are associated with chronic insomnia. Arch Intern Med 2006;166:1262-8.

16. Ohayon MM, Partinen M. Insomnia and global sleep dissatisfaction in Finland. J Sleep Res 2002;11:339-46.

17. Ohayon MM, Hong SC. Prevalence of insomnia and associated factors in South Korea. J Psychosom Res 2002;53:593-600.

18. Ohayon MM, Zulley J. Correlates of global sleep dissatisfaction in the German population. Sleep 2001;24:780-7.

19. Ohayon MM, Smolensky MH, Roth T. Consequences of shiftworking on sleep duration, sleepiness, and sleep attacks. Chronobiol Int 2010; 27:575-89.

20. Ohayon MM. From wakefulness to excessive sleepiness: what we know and still need to know. Sleep Med Rev 2008;12:129-41.

21. Ohayon MM, Priest RG, Zulley J, Smirne S, Paiva T. Prevalence of narcolepsy symptomatology and diagnosis in the European general population. Neurology 2002;58:1826-33.

22. Baldwin CM, Kapur VK, Holberg CJ, Rosen C, Nieto FJ; Sleep Heart Health Study Group. Associations between gender and measures of daytime somnolence in the Sleep Heart Health Study. Sleep 2004;27:305-11.

23. Ohayon MM. Epidemiology of narcolepsy. In Bassetti C, Billiard M, Mignot E. Narcolepsy and Hypersomnia. Series: Lung biology in health and disease. New York: Informa Healthcare 2007:125-132.

24. Lavie P. Incidence of sleep apnea in a presumably healthy working population: a significant relationship with excessive daytime sleepiness. Sleep 1983;6:312-8.

25. Gislason T, Almqvist M, Eriksson G, Taube A, Boman G. Prevalence of sleep apnea syndrome among Swedish men--an epidemiological study. J Clin Epidemiol 1988;41:571-6.

26. Cirignotta F, D’Alessandro R, Partinen M, Zucconi M, Cristina E, Gerardi R, et al. Prevalence of every night snoring and obstructive sleep apnoeas among 30-69-year-old men in Bologna, Italy. Acta Neurol Scand 1989;79:366-72.

27. Martikainen K, Partinen M, Urponen H, Vuori I, Laippala P, Hasan J. Natural evolution of snoring: a 5-year follow-up study. Acta Neurol Scand 1994; $90: 437-42$

28. Ancoli-Israel S, Kripke DF, Klauber MR, Mason WJ, Fell R, Kaplan O. Sleep-disordered breathing in community-dwelling elderly. Sleep 1991; 14:486-95.

29. Stradling JR, Crosby JH. Predictors and prevalence of obstructive sleep apnoea and snoring in 1001 middle aged men. Thorax 1991;46:85-90.

30. Gislason T, Benediktsdóttir B, Björnsson JK, Kjartansson G, Kjeld M, Kristbjarnarson H. Snoring, hypertension, and the sleep apnea syndrome. An epidemiologic survey of middle-aged women. Chest 1993;103:1147-51.

31. Young T, Palta M, Dempsey J, Skatrud J, Weber S, Badr S. The occurrence of sleep-disordered breathing among middle-aged adults. N Engl J Med 1993;328:1230-5.

32. Olson LG, King MT, Hensley MJ, Saunders NA. A community study of snoring and sleep-disordered breathing. Prevalence. Am J Respir Crit Care Med 1995;152:711-6. 
33. Bearpark H, Elliott L, Grunstein R, Cullen S, Schneider H, Althaus W, et al. Snoring and sleep apnea. A population study in Australian men. Am J Respir Crit Care Med 1995;151:1459-65.

34. Bixler EO, Vgontzas AN, Ten Have T, Tyson K, Kales A. Effects of age on sleep apnea in men: I. Prevalence and severity. Am J Respir Crit Care Med 1998;157:144-8.

35. Bixler EO, Vgontzas AN, Lin HM, Ten Have T, Rein J, Vela-Bueno A, et al. Prevalence of sleep-disordered breathing in women: effects of gender. Am J Respir Crit Care Med 2001;163:608-13.

36. Durán J, Esnaola S, Rubio R, Iztueta A. Obstructive sleep apnea-hypopnea and related clinical features in a population-based sample of subjects aged 30 to 70 yr. Am J Respir Crit Care Med 2001;163:685-9.

37. Ip MS, Lam B, Tang LC, Lauder IJ, Ip TY, Lam WK. A community study of sleep-disordered breathing in middle-aged Chinese women in Hong Kong: prevalence and gender differences. Chest 2004;125:127-34.

38. Udwadia ZF, Doshi AV, Lonkar SG, Singh CI. Prevalence of sleep-disordered breathing and sleep apnea in middle-aged urban Indian men. Am J Respir Crit Care Med 2004;169:168-73.

39. Sharma SK, Kumpawat S, Banga A, Goel A. Prevalence and risk factors of obstructive sleep apnea syndrome in a population of Delhi, India. Chest 2006;130:149-56.

40. Reddy EV, Kadhiravan T, Mishra HK, Sreenivas V, Handa KK, Sinha S, et al. Prevalence and risk factors of obstructive sleep apnea among middleaged urban Indians: a community-based study. Sleep Med 2009;10:913-8.

41. Lavigne GJ, Montplaisir JY. Restless legs syndrome and sleep bruxism: prevalence and association among Canadians. Sleep 1994;17:739-43.

42. Phillips B, Young T, Finn L, Asher K, Hening WA, Purvis C. Epidemiology of restless legs symptoms in adults. Arch Intern Med 2000;160:2137-41.

43. Kageyama T, Kabuto M, Nitta H, Kurokawa Y, Taira K, Suzuki S, et al. Prevalences of periodic limb movement-like and restless legs-like symptoms among Japanese adults. Psychiatry Clin Neurosci 2000;54:296-8.

44. Rijsman R, Neven AK, Graffelman W, Kemp B, de Weerd A. Epidemiology of restless legs in The Netherlands. Eur J Neurol 2004;11:607-11.

45. Kim J, Choi C, Shin K, Yi H, Park M, Cho N, et al. Prevalence of restless legs syndrome and associated factors in the Korean adult population: the Korean Health and Genome Study. Psychiatry Clin Neurosci 2005; 59:350-3.

46. Elwood P, Hack M, Pickering J, Hughes J, Gallacher J. Sleep disturbance, stroke, and heart disease events: evidence from the Caerphilly cohort. J Epidemiol Community Health 2006;60:69-73.

47. Phillips B, Hening W, Britz P, Mannino D. Prevalence and correlates of restless legs syndrome: results from the 2005 National Sleep Foundation Poll. Chest 2006;129:76-80.

48. Yokoyama E, Saito Y, Kaneita Y, Ohida T, Harano S, Tamaki T, et al. Association between subjective well-being and sleep among the elderly in Japan. Sleep Med 2008;9:157-64.

49. Juuti AK, Läärä E, Rajala U, Laakso M, Härkänen P, Keinänen-Kiukaanniemi S, et al. Prevalence and associated factors of restless legs in a 57-year-old urban population in northern Finland. Acta Neurol Scand 2010;122:63-9.

50. Rothdach AJ, Trenkwalder C, Haberstock J, Keil U, Berger K. Prevalence and risk factors of RLS in an elderly population: the MEMO study. Memory and Morbidity in Augsburg Elderly. Neurology 2000; 54:1064-8.

51. Ulfberg J, Nyström B, Carter N, Edling C. Prevalence of restless legs syndrome among men aged 18 to 64 years: an association with somatic disease and neuropsychiatric symptoms. Mov Disord 2001;16:1159-63.

52. Ulfberg J, Nyström B, Carter N, Edling C. Restless Legs Syndrome among working-aged women. Eur Neurol 2001;46:17-9.

53. Sevim S, Dogu O, Camdeviren H, Bugdayci R, Sasmaz T, Kaleagasi H, et al. Unexpectedly low prevalence and unusual characteristics of RLS in Mersin, Turkey. Neurology 2003;61:1562-9.

54. Berger K, Luedemann J, Trenkwalder C, John U, Kessler C. Sex and the risk of restless legs syndrome in the general population. Arch Intern Med 2004;164:196-202.
55. Högl B, Kiechl S, Willeit J, Saletu M, Frauscher B, Seppi K, et al. Restless legs syndrome: a community-based study of prevalence, severity, and risk factors. Neurology 2005;64:1920-4.

56. Mizuno S, Miyaoka T, Inagaki T, Horiguchi J. Prevalence of restless legs syndrome in non-institutionalized Japanese elderly. Psychiatry Clin Neurosci 2005;59:461-5.

57. Tison F, Crochard A, Léger D, Bouée S, Lainey E, El Hasnaoui A. Epidemiology of restless legs syndrome in French adults: a nationwide survey: the INSTANT Study. Neurology 2005;65:239-46.

58. Gao X, Schwarzschild MA, Wang H, Ascherio A. Obesity and restless legs syndrome in men and women. Neurology 2009;72:1255-61.

59. Tsuboi Y, Imamura A, Sugimura M, Nakano S, Shirakawa S, Yamada T. Prevalence of restless legs syndrome in a Japanese elderly population. Parkinsonism Relat Disord 2009;15:598-601.

60. Allen RP, Walters AS, Montplaisir J, Hening W, Myers A, Bell TJ, et al. Restless legs syndrome prevalence and impact: REST general population study. Arch Intern Med 2005;165:1286-92.

61. Bjorvatn B, Leissner L, Ulfberg J, Gyring J, Karlsborg M, Regeur L, et al. Prevalence, severity and risk factors of restless legs syndrome in the general adult population in two Scandinavian countries. Sleep Med 2005;6: 307-12.

62. Castillo PR, Kaplan J, Lin SC, Fredrickson PA, Mahowald MW. Prevalence of restless legs syndrome among native South Americans residing in coastal and mountainous areas. Mayo Clin Proc 2006;81:1345-7.

63. Lee HB, Hening WA, Allen RP, Earley CJ, Eaton WW, Lyketsos CG. Race and restless legs syndrome symptoms in an adult community sample in east Baltimore. Sleep Med 2006;7:642-5.

64. Vogl FD, Pichler I, Adel S, Pinggera GK, Bracco S, De Grandi A, et al. Restless legs syndrome: epidemiological and clinicogenetic study in a South Tyrolean population isolate. Mov Disord 2006;21:1189-95.

65. Hadjigeorgiou GM, Stefanidis I, Dardiotis E, Aggellakis K, Sakkas GK, Xiromerisiou G, et al. Low RLS prevalence and awareness in central Greece: an epidemiological survey. Eur J Neurol 2007;14:1275-80.

66. Rangarajan S, Rangarajan S, D'Souza GA. Restless legs syndrome in an Indian urban population. Sleep Med 2007;9:88-93.

67. Ulfberg J, Bjorvatn B, Leissner L, Gyring J, Karlsborg M, Regeur L, et al. Comorbidity in restless legs syndrome among a sample of Swedish adults. Sleep Med 2007;8:768-72.

68. Broman JE, Mallon L, Hetta J. Restless legs syndrome and its relationship with insomnia symptoms and daytime distress: epidemiological survey in Sweden. Psychiatry Clin Neurosci 2008;62:472-5.

69. Cho YW, Shin WC, Yun CH, Hong SB, Kim JH, Allen RP, et al. Epidemiology of restless legs syndrome in Korean adults. Sleep 2008;31:21923.

70. Froese CL, Butt A, Mulgrew A, Cheema R, Speirs MA, Gosnell C, et al. Depression and sleep-related symptoms in an adult, indigenous, North American population. J Clin Sleep Med 2008;4:356-61.

71. Happe S, Vennemann M, Evers S, Berger K. Treatment wish of individuals with known and unknown restless legs syndrome in the community. J Neurol 2008;255:1365-71.

72. Nomura T, Inoue Y, Kusumi M, Uemura Y, Nakashima K. Prevalence of restless legs syndrome in a rural community in Japan. Mov Disord 2008; 23:2363-9.

73. Wesstrom J, Nilsson S, Sundstrom-Poromaa I, Ulfberg J. Restless legs syndrome among women: prevalence, co-morbidity and possible relationship to menopause. Climacteric 2008;11:422-8.

74. Winkelman JW, Shahar E, Sharief I, Gottlieb DJ. Association of restless legs syndrome and cardiovascular disease in the Sleep Heart Health Study. Neurology 2008;70:35-42.

75. Cho SJ, Hong JP, Hahm BJ, Jeon HJ, Chang SM, Cho MJ, et al. Restless legs syndrome in a community sample of Korean adults: prevalence, impact on quality of life, and association with DSM-IV psychiatric disorders. Sleep 2009;32:1069-76.

76. Erer S, Karli N, Zarifoglu M, Ozcakir A, Yildiz D. The prevalence and clinical features of restless legs syndrome: a door to door population study 
in Orhangazi, Bursa in Turkey. Neurol India 2009;57:729-33.

77. Benediktsdottir B, Janson C, Lindberg E, Arnardóttir ES, Olafsson I, Cook E, et al. Prevalence of restless legs syndrome among adults in Iceland and Sweden: Lung function, comorbidity, ferritin, biomarkers and quality of life. Sleep Med 2010;11:1043-8.

78. Celle S, Roche F, Kerleroux J, Thomas-Anterion C, Laurent B, Rouch I, et al. Prevalence and clinical correlates of restless legs syndrome in an elderly French population: the synapse study. J Gerontol A Biol Sci Med Sci 2010;65:167-73.

79. Chen NH, Chuang LP, Yang CT, Kushida CA, Hsu SC, Wang PC, et al. The prevalence of restless legs syndrome in Taiwanese adults. Psychiatry Clin Neurosci 2010;64:170-8.

80. Kim KW, Yoon IY, Chung S, Shin YK, Lee SB, Choi EA, et al. Prevalence, comorbidities and risk factors of restless legs syndrome in the Korean elderly population - results from the Korean Longitudinal Study on Health and Aging. J Sleep Res 2010;19:87-92.

81. Park YM, Lee HJ, Kang SG, Choi HS, Choi JE, Cho JH, et al. Prevalence of idiopathic and secondary restless legs syndrome in Korean Women.
Gen Hosp Psychiatry 2010;32:164-8.

82. Taşdemir M, Erdoğan H, Börü UT, Dilaver E, Kumaş A. Epidemiology of restless legs syndrome in Turkish adults on the western Black Sea coast of Turkey: a door-to-door study in a rural area. Sleep Med 2010;11:82-6.

83. Winkler AS, Trendafilova A, Meindl M, Kaaya J, Schmutzhard E, Kassubek J. Restless legs syndrome in a population of northern Tanzania: a community-based study. Mov Disord 2010;25:596-601.

84. Yilmaz K, Kilincaslan A, Aydin N, Kor D. Prevalence and correlates of restless legs syndrome in adolescents. Dev Med Child Neurol 2011;53: 40-7.

85. Ohayon MM, Roth T. Prevalence of restless legs syndrome and periodic limb movement disorder in the general population. J Psychosom Res 2002; 53:547-54.

86. Picchietti D, Allen RP, Walters AS, Davidson JE, Myers A, Ferini-Strambi L. Restless legs syndrome: prevalence and impact in children and adolescents--the Peds REST study. Pediatrics 2007;120:253-66.

87. Ram S, Seirawan H, Kumar SK, Clark GT. Prevalence and impact of sleep disorders and sleep habits in the United States. Sleep Breath 2010;14:63-70. 